\title{
FERTILE XO MALES AND FEMALES IN THE VARYING LEMMING, DICROSTONYX TORQUATUS PALL.
} (1779)

\section{A UNIQUE GENETIC SYSTEM OF SEX DETERMINATION}

\author{
EMILY A. GILEVA \\ Institute of Plant and Animal Ecology, Urals Scientific Center, Academy of Sciences of the USSR, \\ Sverdlovsk, 620008, USSR \\ and \\ N. A. CHEBOTAR \\ Institute of Experimental Medicine, Academy of Medical Sciences of the USSR, Leningrad, 197022,
}

Received 13.vii.78

\section{SUMMARY}

In the varying lemming, only some of the females exhibit a conventional sex chromosome constitution, XX. Many fertile females as well as all males have one $\mathrm{X}$ chromosome. The $\mathrm{Y}$ chromosome was not revealed by the methods employed. It has been shown that the sex of XO specimens depends on a genetic factor which displays two alternative forms. The XO lemmings possessing the $m$-form develop as males; those carrying the $f$-form develop as females. This factor is most likely $\mathrm{X}$-linked. The $\mathrm{XX}$ females are heterozygous for this factor or homozygous for the $m$-form. In progeny of the $\mathrm{XO}$ and heterozygous XX females an excess of daughters is observed, the secondary sex ratio being 0.67 and 0.75 respectively. Two or three mutational events must have given rise to this complex system of sex determination. The possible adaptive significance of the relevant system is discussed.

\section{InTRODUCtion}

THE genetical mechanisms of sexual differentiation in mammals still present a problem in many respects (number, location, mode of action of genes involved, etc.). An unusual system of sex determination has been discovered in two subspecies of varying lemming, Dicrostonyx torquatus torquatus and $D . t$. chionopaes. We reported earlier on the exceptional sex chromosome constitution and unbalanced sex ratio in these forms; an appreciable excess of females was observed in both subspecies (Gileva, 1973, 1975). Cytological observations and extensive breeding experiments within a laboratory colony of $D$. $t$. chionopaes are described below. We should like to mention that all our findings are fully consistent with those obtained in the captive stock of $D$. $t$. torquatus from the Polar Urals (corresponding data will be reported elsewhere). The location and interaction of sex determinants and mutational events that have given rise to a unique system of sex determination in varying lemming are discussed.

\section{Materials AND methods}

This study was based on 1600 animals from a colony established with eight lemmings captured on the Laptev Sea coast (Buor-Khaya inlet); 858 specimens were karyotyped, mitotic chromosome preparations being 
obtained from bone marrow, spleen and testes. G-banding was performed according to the method of Seabright (1972). Meiotic chromosomes of males were studied by the method of Evans et al. (1964). For studies of meiosis in females the technique of Tarkovsky (1966) was employed.

Animals were sexed at weaning. The loss of young before weaning was shown not to affect the sex ratio (Benenson, 1978). Sex ratio was defined as the proportion of females.

\section{Results}

The chromosome complement of $D$. t. chionopaes was found to be identical in bone marrow, spleen and spermatogonia. It consists of $46 \mathrm{~A}$ chromosomes and one to eight small bi-armed B chromosomes. Autosomes include two pairs of small metacentrics, two pairs of subtelocentrics and 18 pairs of acrocentrics (fig. IA). All the chromosome pairs were identified by their G-banding patterns (fig. 2). As we have already pointed out, varying lemming were found to have a unique sex chromosome system; 395 of the females karyotyped had two $\mathrm{X}$ chromosomes. The metacentric $\mathrm{X}$ is the largest chromosome of the complement with a mean arm ratio of $1 \cdot 2$. Its relative length forms 14.8 per cent \pm 0.3 of the haploid set. At diakinesis in XX females a large symmetrical bivalent formed by two X's was observed (fig. 3).

The other 242 females and all the 221 males exhibited an identical karyotype. Besides autosome pairs they possessed only one $\mathrm{X}$ chromosome and a large unpaired acrocentric chromosome (figs. I and 2). One could assume it to be the $\mathrm{Y}$ chromosome. To verify this supposition we examined the size, G-bands and meiotic behaviour of the unpaired element. It proved to be identical to the long arm of the $\mathrm{X}$ both in size and G-banding pattern. At meiosis of males and females possessing the odd chromosome an unequal bivalent with lateral pairing lacking in XX females was seen (figs. 4 and 5). The exceedingly large symmetrical bivalent discovered in XX females was absent here. The unpaired part of the larger member of the unequal bivalent was often negatively heteropycnotic at diakinesis and always isopycnotic at late metaphase $\mathrm{I}$. There seems to be no doubt that the unequal bivalent was formed by the $\mathrm{X}$ and the relevant odd chromosome. The latter as seen from its size, G-banding and meiotic behaviour is homologous to the long arm of the X. Hence, all the males and females of $D$. $t$. chionopaes possess in fact a double amount of genetic material which the odd chromosome consists of, either in the form of two long arms of the X's (XX females) or in the form of the same arm of the $\mathrm{X}$ coupled with the unpaired chromosome (the other females and males). Therefore, the odd element of the varying lemming karyotype must be classified as an autosome (referred to hereafter as no. 5 or A5). It is very likely that the relevant autosome was translocated on to the original $\mathrm{X}$ and this event has brought about the modern $\mathrm{X}$ of $D$. $t$. chionopaes. Indeed, the heteropycnotic state of the short arm of the $\mathrm{X}$ at diakinesis and its relative length (6.7 per cent \pm 0.2 of haploid set) are consistent with the peculiarities of the mammalian original X (Ohno, 1967).

Thus we have not succeeded in finding the $\mathrm{Y}$ chromosome in $D . t$. chionopaes by any of the methods used. However, one more possibility should be examined. It has been stated above that B chromosomes were 
discovered in the varying lemming. They vary in number and at meiosis often occur as univalents. It is known that in some mammals the $Y$ can be completely separated from the $\mathrm{X}$ at late prophase and metaphase 1 (Fredga, 1971). It may be possible, therefore, that the $\mathrm{Y}$ of varying lemming being similar to the B's in size and meiotic behaviour is concealed among them. To check this, mean numbers of chromosomes in males and females of both types were compared. If the males had the $\mathrm{Y}$ chromosome, they would have on the average one chromosome more than females (provided random segregation takes place at meiosis). However, the mean chromosomal number proved to be the same in all the three groups of $D$. $t$. chionopaes $(50.0 \pm 0.09$ in males, $49.8 \pm 0.12$ in females with one $X$ and $50.1 \pm 0.09$ in $\mathrm{XX}$ females). Consequently, it is unlikely that the $\mathrm{Y}$ could be taken for a B chromosome. Besides, three males of $D$. $t$. torquatus (the other subspecies studied) have been found to be without B chromosomes. The Y chromosome was not revealed in their karyotypes either.

Thus we may conclude that in $D$. $t$. torquatus the $\mathrm{Y}$ chromosome as a separate member of karyotype is not present. The same is encountered in many mammals which display Y autosome translocations (Fredga, 1971). In some species the translocated part of the $\mathrm{Y}$ is very small and may be detected only by special methods, the loss in these cases of most of the $\mathrm{Y}$ chromosome seems not to affect the viability and fertility of males ( $\mathrm{Ma}$ et al. 1976; de la Maza and Sawyer, 1976). In the varying lemming, however, cytological evidence does not support the existence of a translocation, even of a small part of the $\mathrm{Y}$. We shall return to this question later, and until then it seems quite reasonable to regard males and some of the females of $D$. $t$. chionopaes as having an XO constitution.

All the XO females and males appeared to have a normal phenotype and fertility. When paired with males, the $\mathrm{XO}$ dams produced offspring as often as the XX females (about 90 per cent of paired females of both types gave birth to the young). The XO females of the mouse are fertile too, but they are rare, with a frequency of less than 1 per cent (Cattanach, 1974). It is believed that the occurrence of XO females may result from occasional sex chromosome non-disjunction in parental germ line cells. However, neither in oogenesis nor in spermiogenesis of varying lemming has sex chromosome non-disjunction been discovered (these data will be reported in detail elsewhere). We may suppose that the high frequency of XO females, the identity of karyotypes of these females and males and an exceptional sex ratio are interrelated and have a common genetic basis. This relationship is confirmed by our extensive breeding experiments. The results demonstrate certain regularities in the occurrence of XO females and unbalanced sex ratio which can be described as follows:

The females examined can be divided into three types taking into consideration their own chromosome constitution, that of their daughters and the secondary sex ratio in their offspring.

1. XX females producing XX daughters only. Sex ratio in their litters is balanced.

2. XX females producing both $\mathrm{XX}$ and $\mathrm{XO}$ daughters. Prevalence of females in their progeny is observed.

3. XO females producing both $\mathrm{XX}$ and $\mathrm{XO}$ daughters. Excess of females in their progeny is seen.

The following hypothesis can be proposed for the explanation of these 
breeding data and cytological records. It seems to be plausible that the sex of $\mathrm{XO}$ specimens of varying lemming depends after all on the X-linked factor which displays two alternative forms. The $\mathrm{XO}$ animals possessing one form $(m)$ develop as males; those carrying the other form $(f)$ exhibit feminine differentiation. The possible nature and pattern of functioning of this $m f$-factor will be discussed below; the proposed mode of its inheritance is presented in scheme 1 (table 1 ).

This hypothesis has been substantiated by analysing the sex chromosome constitution and the secondary sex ratio in animals from several (10-11) captive generations and by comparing the results with values expected on the basis of scheme 1 (table 1 ).

TABLE 1

Scheme 1. Inheritance of $X$-linked $\mathrm{mf}$-factor participating in sex determination in varying lemming. Sex chromosome constitution of somatic cells and gametes in parents and their offspring are presented. $X^{\mathrm{m}}$ is the $X$ chromosome with $\mathrm{m}$-form; $X^{\mathrm{P}}$ is the $X$ chromosome with f-form

Males $\left\{\begin{array}{l}\overbrace{\text { Soma }}^{\text {Soma }} \\ \mathrm{X}^{m} \mathrm{O} \\ \end{array}\right.$

(i) Male analysis

According to the scheme, all the males are identical as to their sex chromosome genotype in possessing only an $\mathrm{X}^{m}$ chromosome; and each of them is able to sire progeny of any type. Indeed, such a situation has been observed in experiments on replacing partners in 38 parental pairs. Sire replacement has not affected the sex ratio and the sex chromosome constitution of progeny of the dam. Meanhile the same male being mated with females of various types was able to produce progeny differing in sex chromosomes and sex ratio depending on the type of the mother.

\section{(ii) Female analysis}

As stated above, all females of our captive stock could be divided into three types in accordance with their own sex chromosome constitution and that of their female progeny. It was necessary to examine whether these three types corresponded to the postulated lst $\left(\mathrm{X}^{m} \mathrm{X}^{m}\right)$, 2nd $\left(\mathrm{X}^{m} \mathrm{X}^{f}\right)$ and $3 \mathrm{rd}\left(\mathrm{X}^{f \mathrm{O}}\right)$ types of females. If they did, the progeny of dams of every observed type should exhibit a different secondary sex ratio and specific frequencies of XO and XX daughters (see scheme 1). Progenies of 77 females from the $D$. $t$. chionopaes captive stock have been analysed from this point of view. It was extremely important to find criteria for distinguishing females of various types. As mentioned earlier, XO females presumably 
carrying $\mathrm{X}^{f}$ are cytologically readily recognisable. But $\mathrm{X}^{m} \mathrm{X}^{m}$ and $\mathrm{X}^{m} \mathrm{X}^{f}$ females cannot be distinguished cytogenetically and are discerned only by their progeny. According to our hypothesis $\mathrm{XX}$ females are able to give birth to $\mathrm{XO}$ daughters only if they transmit the $\mathrm{X}^{f}$ chromosome. We can therefore classify the $\mathrm{XX}$ female as an $\mathrm{X}^{m} \mathrm{X}^{f}$ type if she has produced at least one XO daughter. Similarly, the inability to produce XO daughters should be the distinguishing feature of $\mathrm{X}^{m} \mathrm{X}^{m}$ females. However, $\mathrm{XO}$ daughters may not be found in the progeny of a certain $\mathrm{X}^{m} \mathrm{X}^{f}$ female if the number of her examined daughters is not sufficiently large. It is therefore necesssary to determine the number of XX daughters (if there are no $\mathrm{XO}$ ones) that must be found in the progeny of an XX dam to consider her as the $\mathrm{X}^{m} \mathrm{X}^{m}$ type at the chosen level of sgnificance. This number was determined from the proportion of $\mathrm{XX}$ and $\mathrm{XO}$ females in the progeny of $\mathrm{X}^{m} \mathrm{X}^{f}$ dams as suggested by our hypothesis. As seen from scheme 1 (table 1) the ratio of $\mathrm{XX}$ and $\mathrm{XO}$ females should be $2: 1$. Then the probability of a random occurrence of $n \mathrm{XX}$ daughters and not a single $\mathrm{XO}$ in the progeny of an $\mathrm{X}^{m} \mathrm{X}^{f}$ female is $(2 / 3)^{n}$. If a 5 per cent level of significance is chosen, $n$ being calculated from the expression $(2 / 3)^{n}=0.05$ is $7 \cdot 4$. Hence an XX dam that gave birth to not less than eight XX daughters none of them $\mathrm{XO}$, should be classified as an $\mathrm{X}^{m} \mathrm{X}^{m}$ female at the 5 per cent level of significance.

Thus we were able to divide the dams into three types according to their supposed sex chromosome genotypes and then to examine the correspondence of certain of their offspring characteristics to those we assumed on the grounds of our hypothesis. The results of this analysis are presented in table 2.

\section{TABLE 2}

Progeny of diverse female types of $\mathrm{D}$. torquatus

Number of females mated

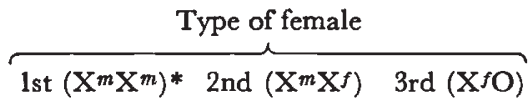

Total numbers of litters

Mean sex ratio in litters

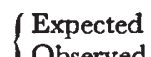

$$
8
$$

25

44

54

0.50

133

171

Observed

0.55

0.75

0.73

0.67

Number of XX daughters $\left\{\begin{array}{l}\text { lst type at } 9 \% \\ \text { level of } \\ \text { significance } \\ \text { 2nd type } \\ \text { Unknown type } \\ \text { Totals }\end{array}\right.$

Number of the 3rd type

daughters

Proportion of XX females (Expected

among daughters karotyped $\{$ Observed

7
70
77

11
10
97
118

$$
0.68
$$

$\begin{array}{ccc}- & 74 & 95 \\ 1.0 & 0.67 & 0.50 \\ 1.0 & 0.61 & 0.49\end{array}$

* Combined data on $D . t$. chionopaes and D. t. torquatus are presented here.

(a) First type of females, $X^{\mathrm{m}} X^{\mathrm{m}}$

From scheme 1 (table 1) we see that all female progenies of the lst type dams of any generation are expected to have an $\mathrm{X}^{m} \mathrm{X}^{m}$ constitution too. 
Experimental records are consistent with this prediction. As table 2 shows, eight females were clasified as the $\mathrm{X}^{m} \mathrm{X}^{m}$ type because they produced only XX daughters (eight or more each of them, 77 altogether). Seven of these daughters were mated and each gave birth to six to seven $\mathrm{XX}$ females and to none of $\mathrm{XO}$ and so could be considered as the $\mathrm{X}^{m} \mathrm{X}^{m}$ type at a 9 per cent level of significance. Moreover, we karyotyped 127 female progenies of the second to eighth generations descending from initial $\mathrm{X}^{m} \mathrm{X}^{m}$ dams. They all proved to have an XX consitutition. Thus the absence of $f$-form of the postulated X-linked factor in females under consideration was confirmed.

\section{(b) Second type of females, $X^{\mathrm{m}} X^{\mathrm{f}}$}

In the progeny of these dams all the three types of daughter were expected, and the number of $\mathrm{XX}$ females should be double that of $\mathrm{XO}$ females. Experimental data presented in table 2 are in favour of this prediction.

\section{(c) Third type of females, $X^{\mathrm{f}} O$}

Before considering the offspring of these females it is necessary to discuss the problem of $m f$-factor location. We should bear in mind that the $\mathrm{X}$ chromosomes of $D$. $t$. chionopaes is complex and includes a large autosomal portion homologous to autosome no. 5 (long arm). The $m f$-factor can be located on either this autosomal part or on the short arm corresponding to the original $\mathrm{X}$. The possibility of this factor being located on another autosome besides the 5 th should be examined. Both autosomal and sexlinked genes may take part in sex differentiation of mammals (Mittwoch, 1973). If the $m f$-factor is situated on the short arm of the $\mathrm{X}$, the progeny of XO females must be consistent with scheme 1 (table 1). This means that $\mathrm{XO}$ females can produce only $\mathrm{X}^{m} \mathrm{X}^{f}$ and $\mathrm{X} f \mathrm{O}$ daughters. If the factor in question were located on the autosomal part of the $\mathrm{X}, \mathrm{XO}$ females could produce eggs carrying the $\mathrm{X}^{m}$ chromosome as a result of a crossingover between the long arm of the $\mathrm{X}$ and the autosome no. 5 which might have the $m$-form. In this case XO dams could give birth not only to the 2 nd and 3rd type daughters, but to the lst type as well. The same progeny (all the three types of daughters) should be observed in XO females if the $m f$ factor were located on another autosome, the $f$-form being dominant and expressed only in XO specimens (provided the meiotic segregation of the relevant autosome and the $\mathrm{X}$ were independent). In both cases the dams of the 1 st and 2 nd types would produce the same progeny as if the $m f$-factor were really $\mathrm{X}$-linked (see scheme 2 , table 3 ). It should be noted that if the $m f$-factor is autosomal, the $f$-form cannot be recessive, this would contradict our breeding records.

As seen from table 2, XX and $\mathrm{XO}$ daughters were observed in the progeny of $\mathrm{XO}$ females in expected proportions. Of eight daughters of $\mathrm{XO}$ dams who gave birth to young, seven produced $\mathrm{XX}$ and $\mathrm{XO}$ females and hence belonged to the 2 nd type. The eighth female (no. 951) gave birth to eight daughters, and when karyotyped all had the XX constitution. This female is not included in table 2 because of the difficulty of determining exactly her type. As stated above, such a single female could be classified as a lst type female at a 5 per cent level of significance. In the case of the no. 951, however, it was necessary to estimate the probability 
a) $\$ \times 0$

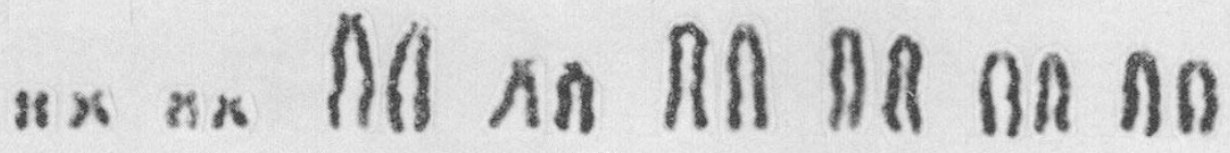

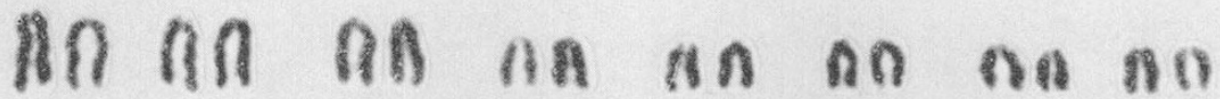

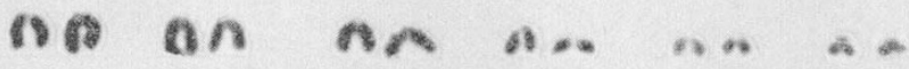

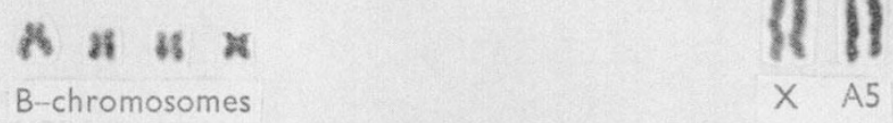

b) $q X X$

c) $\pi$
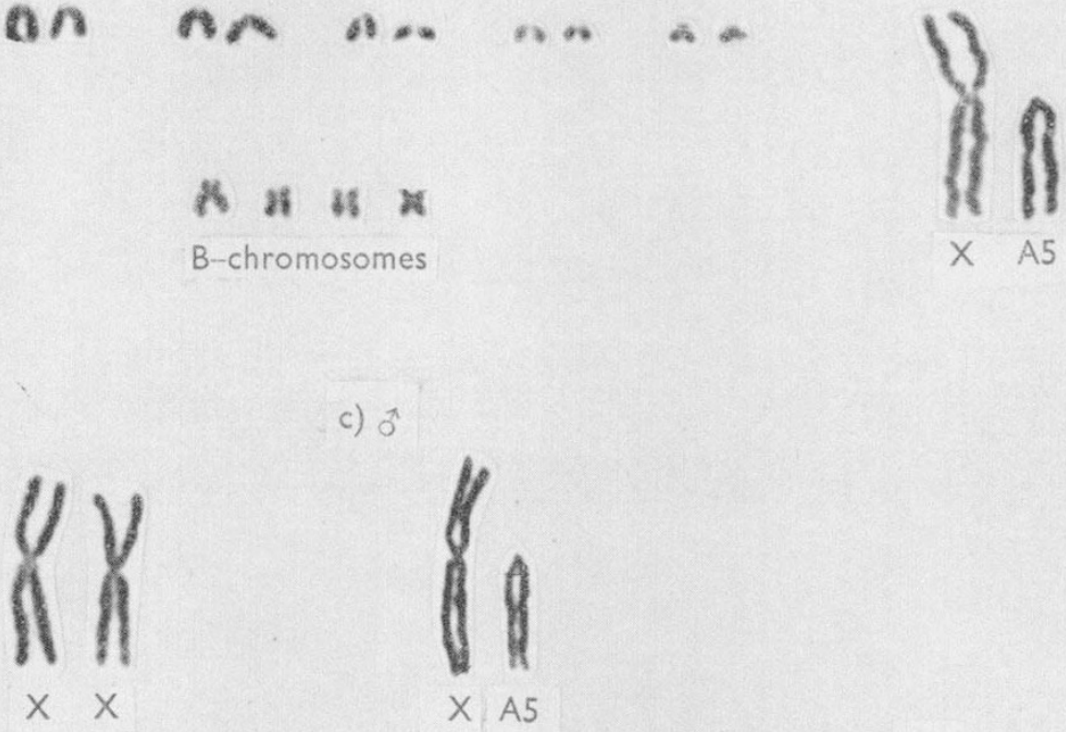

FIG. 1.-Mitotic chromosomes of D. t. chionopaes. A, Karyotype of XO female. B, Sex chromosomes of XX female. $\mathrm{C}, \mathrm{X}$ chromosome and unpairable autosome N5 of a male. 

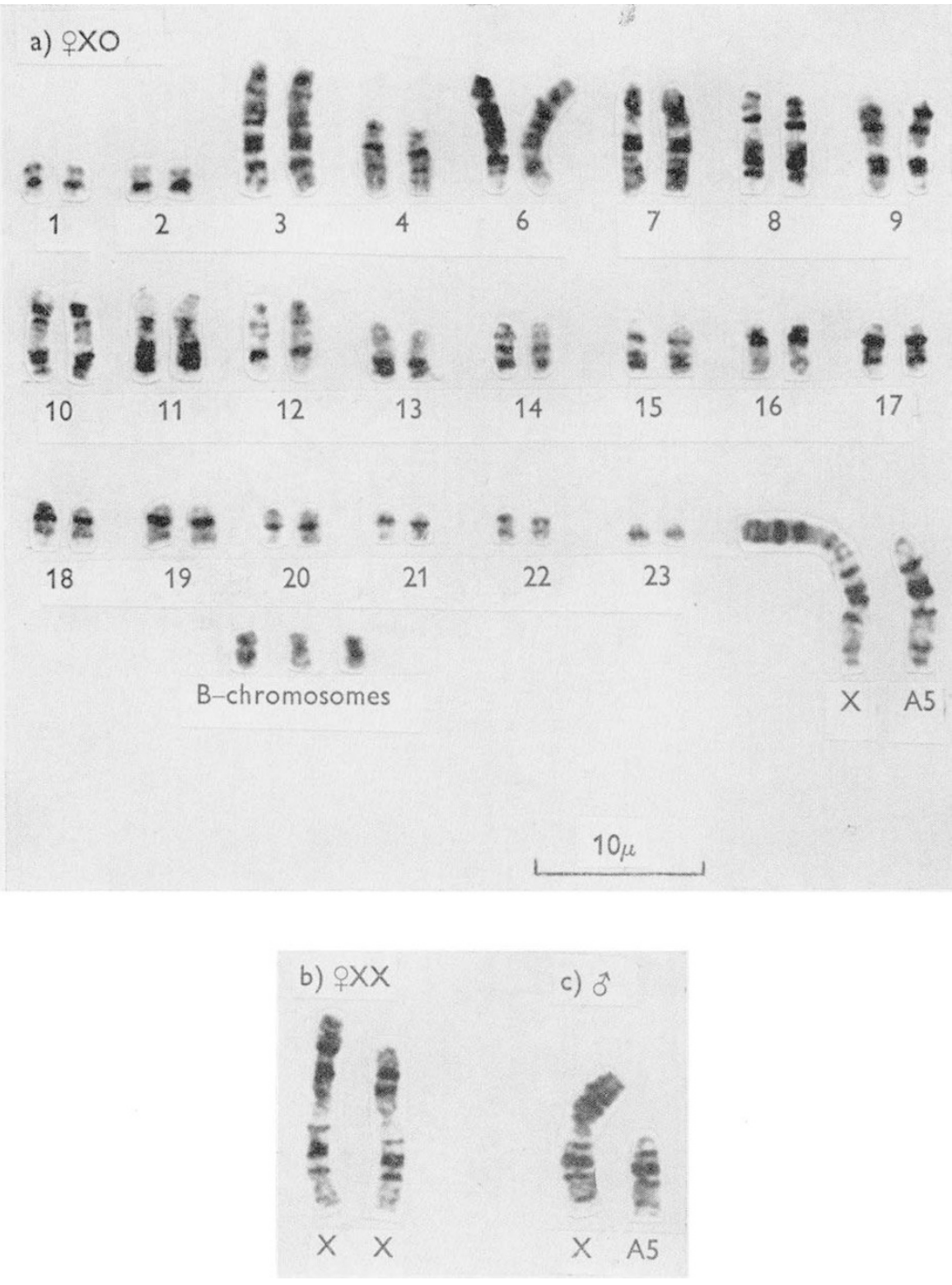

Plate II

FIG. 2.-G-banded chromosomes of D. t. chionopaes. A, Karyotype of XO female. B, Sex chromosomes of XX female. $\mathrm{C}, \mathrm{X}$ chromosome and autosome N5 of a male. 

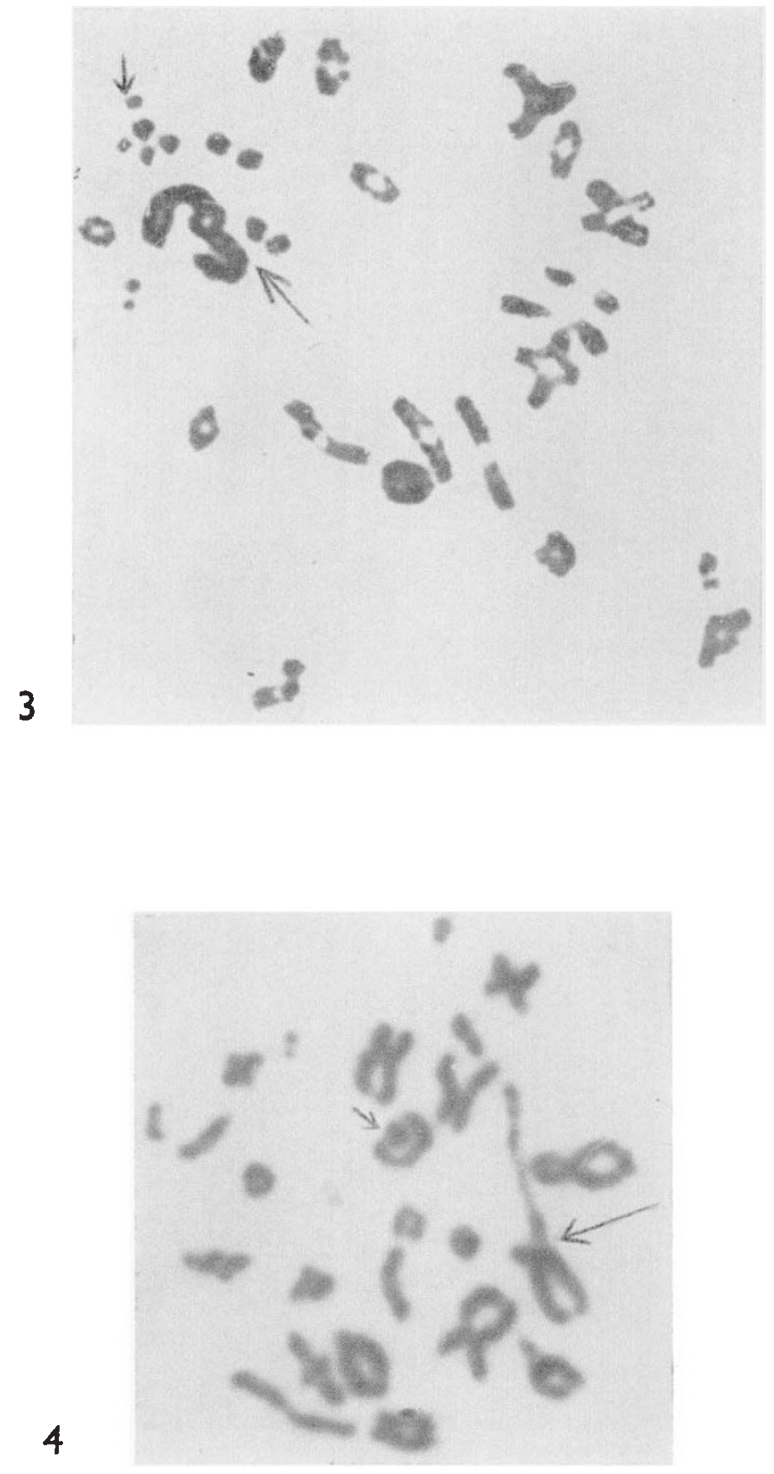

Plate III

Frg. 3.-Diakinesis in XX female of D. t. chionopaes. Arrows indicate univalent formed by the $\mathrm{B}$ and sex bivalent.

Frg. 4.-Diakinesis in a male of D. t. chionopaes. Arrows indicate univalent formed by the B and unequal bivalent composed of $\mathrm{X}$ chromosomes and autosome N5. 


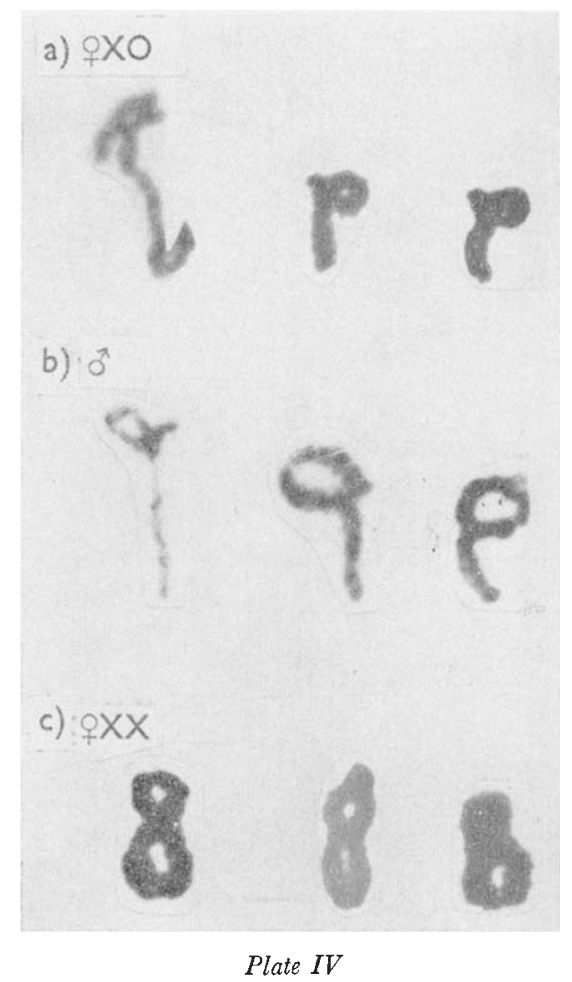

FIG. 5.-Sex bivalent from meiotic cells of D. t. chionopaes. A, XO fernales. B, Males. $\mathrm{C}, \mathrm{XX}$ fernales. 


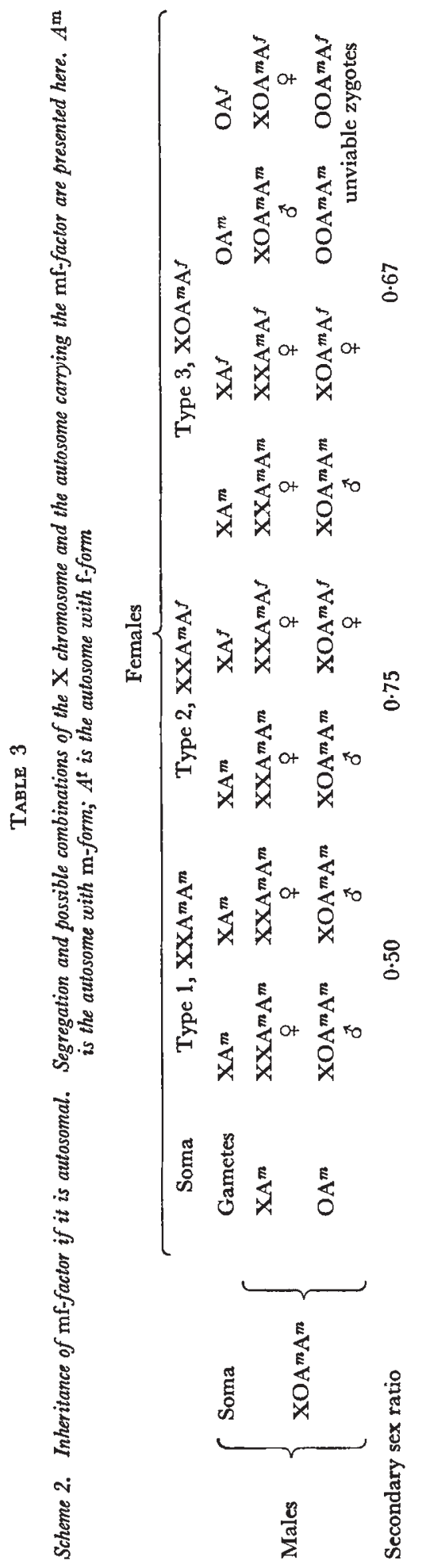


of occurrence of a group of eight $\mathrm{X}^{m} \mathrm{X}^{f}$ females, one of which could produce eight XX daughters and not a single $\mathrm{XO}$. This probability computed on the basis of the binomial law proved to be rather large, 0-26. Thus the exact type of the no. 951 female remained uncertain. It is clear that far more extensive breeding data are necessary to decide whether $\mathrm{XO}$ females can produce $\mathrm{X}^{m} \mathrm{X}^{m}$ daughters. If they can, it means most probably that the $m f$-factor is situated on autosome no. 5 (hence on the long arm of $\mathrm{X}$ ) or on another autosome. However, at present most experimental findings are in favour of $m f$-factor being X-linked.

\section{(iii) Secondary sex ratio}

The expected sex ratio in progeny of diverse types of females were estimated on the basis of the scheme of $m f$-factor inheritance. These estimates perfectly agree with the observed values in all the three types of females (table 2).

\section{Discussion}

All the data on breeding and cytology of $D$. $t$. chionopaes are compatible with the hypothesis concerning the existence of the genetic $m f$-factor controlling the sex of XO individuals. At present it is difficult to ascertain exactly the nature of this factor, because of our incomplete understanding of sex-determining mechanisms in mammals. However, some views may be expressed.

It is reasonable to assume that the $m f$-factor is a single gene with two alleles $(m$ and $f)$. As has already been pointed out, X-linked and possibly autosomal genes participate in masculine differentiation in mammals. Their mutation results in syndromes of testicular feminisation (Lyon and Hawkes, 1970) and in pure gonadal dysgenesis (Sternberg et al., 1968). In the wood lemming, Myopus schisticolor numerous fertile females with male sex chromosome constitution have been discovered (Fredga et al., 1976). Since wood lemming and varying lemming are rather closely related species, it is reasonable to suppose that the genetic mechanisms responsible for the appearance of exceptional females are similar in both species in general outline. It should be noted however that in $M$. schisticolor the females in question and males as well possess the $\mathrm{Y}$ chromosome as a separate member of the set. There is evidence that XY specimens of wood lemming develop as females due to the suppressive effect of an X-linked mutant gene acting on the male determining locus (loci) of the Y (Fredga et al., 1977). Although the $\mathrm{Y}$ chromosome has not been found in varying lemming, $\mathrm{XO}$ specimens are assumed to have a certain sex determinant which is absent in $\mathrm{XX}$ specimens. In this way it can be explained that the $\mathrm{X}^{m} \mathrm{X}^{m}$ lemmings are normal females while the $\mathrm{X}^{m} \mathrm{O}$ are fertile males. It is known that XO mammals usually exhibit feminine differentiation and on the other hand the presence of two X's in some cases does not hinder the development of human and mouse specimens as males (Cattanach, 1974).

If the conditions in $D$. torquatus and $M$. schisticolor are analogous, the relevant sex determinant might be a submicroscopic translocation of part of the Y containing male-determining gene(s). Then the $f$-form of postulated X-linked factor in varying lemming corresponds to the $\mathrm{X}$-linked 
mutant gene which affects the male determining action of the $\mathrm{Y}$ in wood lemming, the $m$-form corresponding to the gene's normal allele. In $M$ schisticolor, however, the autosomal linkage of the gene corresponding to $m f$-factor cannot be excluded either. If the mutant gene were located on the $\mathrm{X}, \mathrm{XY}$ females would have to give birth exclusively to daughters, as they produce only $\mathrm{X}$-carrying eggs (because of non-disjunction of sex chromosome in foetal ovaries). In fact, however, a noticeable part of XY females gave birth to sons (Fredga et al., 1977). A possible cause of this phenomenon is that the relevant mutant gene is autosomal, being dominant and male-limited in action.

The most probable location of the translocated part of the $\mathrm{Y}$ (or male determinant of some other nature) in the varying lemming seems to be the autosome no. 5, absent in XX specimens as a separate set member. Otherwise we should observe in varying lemming an abundance of gametes and zygotes with unbalanced male and female sex determinants or a meiotic system of non-random segregation preventing the occurrence of such an unbalance. We have not found such phenomena in $D$. torquatus, so it seems most likely that the male determinant is situated on the autosome no. 5 . As shown above, however, none of the cytological methods employed has revealed the translocation of even a small piece of the $\mathrm{Y}$ on this autosome or on any other chromosome. Although it can be assumed that the translocated part of the $\mathrm{Y}$ is too small to be detectable, another possibility to be taken into consideration is the complete loss of the $\mathrm{Y}$ chromosome. The development of a male phenotype was observed in some XX specimens of the mouse (Cattanach et al., 1971), the goat (Soller et al., 1969) and the human (Wachtel et al., 1976). This condition, often called sex reversal, is inherited as an autosomal trait, dominant (mouse) or recessive (goat). Though in these cases also a submicroscopic $\mathrm{Y}$ autosome translocation cannot be fully excluded, another possible interpretation is that the masculine differentiation of animals in question is induced by mutant autosomal gene(s). The data on the goat where the sex reversal factor behaves as recessive are especially difficult to interpret in terms of $\mathrm{Y}$ autosome translocation (Cattanach, 1974). It should be assumed, therefore, that in varying lemming the male determinant situated on autosome no. 5 is a mutant autosomal gene which, being located in the pericentromeric region, does not undergo crossingover.

Thus it is most likely that the sex of XO specimens of $D$. torquatus is dependent on the interaction of the X-linked $m f$-factor and the male determinant situated on autosome no. 5. The nature of this interaction is not yet clear. Fredga et al. (1977) supposed that in wood lemming the mutant Xlinked gene suppressed or failed to activate the Y-linked structural gene for $\mathrm{H}-\mathrm{Y}$ antigen which is often considered as primary male-determining gene product. However, in the interpretation of the case with the varying lemming the complete absence of the $\mathrm{Y}$ chromosome must be taken into account. It should be noted that the location of the structural locus for $\mathrm{H}-\mathrm{Y}$ antigen is not known exactly. Although most of the data supports Y-linkage of the $\mathrm{H}-\mathrm{Y}$ structural gene, there is evidence that the gene in question is situated on the $\mathrm{X}$ chromosome or an autosome and only regulatory elements controlling the H-Y locus are located on the Y (Bjersing, 1977; Wachtel, 1977). If so, the simple genetic model of the situation in $D$. torquatus is that the male determinant located on autosome no. 5 possesses a regulatory function with 
respect to $m f$-factor which corresponds to the structural locus for H-Y antigen. Then $m$-form appears to be the normal allele that produces H-Y antigen only in the presence of the male determinant and $f$-form the mutant allele which has lost this ability. Therefore, the primary testis-determining gene product is present in $\mathrm{X}^{m} \mathrm{O}$ embryos and they differentiate as males; in $\mathrm{X}^{f \mathrm{O}}$ specimens it is absent and they develop as females. $\mathrm{X}^{m} \mathrm{X}^{m}$ and $\mathrm{X}^{f} \mathrm{X}^{m}$ specimens are females because they have no male determinant situated on the autosome no. 5 .

The unusual system of sex determination in $\mathrm{XO}$ specimens of the varying lemming probably evolved after at least two or three mutational events. One of the events was the appearance of the $m f$-system including the mutant $f$-form; the second one strengthened the autosomal control of male differentiation either by $\mathrm{Y}$ autosome translocation or by mutation of a prerequisite autosomal gene. The latter resulted in the mutant allele being able to direct sexual differentiation towards the male mode without the Y chromosome. In this case there should occur a third mutational event, namely, the loss of the $\mathrm{Y}$. We may suppose that only the first event has taken place in the wood lemming by this time.

It seems most likely that the complicated genetic mechanism of sexual differentiation discovered in lemmings has an adaptive significance probably connected with population regulation. From this point of view daughter excess in the progeny of females carrying $f$-factor is especially important as sex ratio is one of the main demographic parameters determining population dynamics. By now we have examined 13 females from natural populations of $D$. torquatus. Twelve of them proved to have an $\mathrm{X}^{f}$ chromosome. In polygamous species such as lemmings an abundance of females can bring about a rapid increase of density. Indeed, in varying lemmings on Wrangel island an excess of females (63 per cent) was observed just before the peak of density while at other phases of the population cycle the sex ratio was nearly balanced (Chernyavsky, 1978). Changes of frequencies of the two $m f$-factor forms probably account for these fluctuations in sex ratio and hence can be considered as one of the possible genetic mechanisms responsible for the population dynamics in lemmings.

Acknowledgments. -We are grateful to Professor A. P. Dyban and Dr G. V. Derjagin for their helpful discussion and to Dr A. V. Pokrovsky for performing animal breeding. We also thank Mr G. M. Rogalsky and Mrs C. C. Potapenko for their assistance in preparing the manuscript.

\section{REFERENCES}

BENENSON, I. E. 1978. Investigation of secondary sex ratio in laboratory colonies of certain rodents. Proceedings of Institute of Plant and Animal Ecology, Sverdlovsk, 7-8 (in Russian). BJERsing, L. 1977. H-Y antigens and sexual differentiation. Lancet, N8006, 311.

CAtTANACH, B. M. 1974. Genetic disorders of sex determination in mice and other mammals. In: Birth Defects. Proceedings of the Fourth International Conference, Vienna, 1973, 129-141. CATTANACH, B. M., POLLARD, c. E., AND HAWKes, s. G. 1971. Sex-reversed mice: XX and XO males. Cytogenetics, 10, 318-337.

Cherny avsky, F. B. 1978. Population cycles of Siberian and varying lemmings on Wrangel island. Transactions of the Second Congress of the Theriological Society of the USSR, Moscow, 210-212 (in Russian).

EVANS, E. P., BRECKON, G., AND FORD, C. E. 1964. An air-drying method for meiotic preparations from mammalian testes. Cytogenetics, 3, 289-294.

FREDGA, K. 1971. Unusual sex chromosome inheritance in mammals. Philosophical Transactions of the Royal Society of London, 259B, 15-36. 
FREDGA, K., GROPP, A., WINkIng, H., AND Frank, F. 1976. Fertile XX-and XY-type females in the wood lemming, Myopus schisticolor. Nature, 261, 225-228.

FREDGA, K., GROPP, A., WINKING, H., AND FRANK, F. 1977. A hypothesis explaining the exceptional sex ratio in the wood lemming (Myopus schisticolor). Hereditas, 85, 101-104.

GILEVA, E. A. 1973. B-chromosomes, unusual inheritance of sex chromosomes and sex ratio in the varying lemming, Dicrostonyx torquatus torquatus Pall. (1779). Proceedings of the Academy of Sciences of the USSR, 213, 952-955 (in Russian).

GILEVA, E. A. 1975. Karyotype of Dicrostonyx torquatus chionopaes Allen and unusual chromosomal mechanism of sex determination in Palaearctic varying lemmings. Proceedings of the Academy of Sciences of the USSR, 224, 697-700 (in Russian).

LYON, M. F., AND HAWKEs, s. G. 1970. X-linked gene for testicular feminization in the mouse. Nature, 227, 1217-1219.

MA, N. S. F., ELLIOTT, M. W., MORGAN, L., MILlER, A., AND JONES, T. C. 1976. Translocation of $Y$ chromosome to an autosome in the Bolivian owl monkey, Aotus. American Journal of Physical Anthropology, 45, 191-201.

DE LA MAZA, L. M., AND SAWYER, J. R. 1976. The $\mathbf{G}$ and $Q$ banding pattern of Ellobius lutescens. A unique case of sex determination in mammals. Canadian Journal of Genetics and Cytology, 18, 497-502.

MrтTWOch, v. 1973. Genetics of sex differentiation. Academic Press, New York-London.

онno, s. 1967. Sex chromosomes and sex-linked genes. Springer, Berlin-Heidelberg-New York.

SEABRIGHT, M. 1972. The use of proteolytic enzymes for the mapping of structural rearrangements in the chromosomes in man. Chromosoma, 36, 204-210.

SOLLER, M., PADEH, B., WYSOKI, M., AND AYALON, N. 1969. Cytogenetics of Saanen goats showing abnormal development of the reproductive tract associated with the dominant gene for polledness. Cytogenetics, 8, 51-67.

STERNBERG, W. H., BARCLAY, D. L., AND KLOEPFER, H. W. 1968. Familial XY gonadal dysgenesis. New England Journal of Medicine, 278, 695-700.

TARKovsKY, A. K. 1966. An air-drying method for chromosome preparations from mouse eggs. Cytogenetics, 5, 394-400.

WACHTEL, s. s. 1977. H-Y antigen: genetics and serology. Immunological Reviezes, 33, 33-58.

WACHTEL, S. s., KOO, G. G., BREG, W. R., THALER, H. T., DILLARD, G. M., ROSENTHAL, I. M., DOSIK, H., GERALD, P. S., SAENGER, P., NEW, M., LIEBER, E., AND MILLER, O. J. 1976. Serologic detection of a Y-linked gene in $\mathrm{XX}$ males and $\mathrm{XX}$ true hermaphrodites. New England Journal of Medicine, 295, 750-754. 